\title{
Tourism in Kenya's national parks: A cost-benefit analysis
}

\section{Hubert Cheung}

Department of Integrative Biology, College of Biological Science, University of Guelph, Guelph, ON Canada. Faculty supervisor: John Fryxell. For correspondence, please email: hcheung7@hotmail.com.

\section{Abstract}

East Africa is home to some of the most stunning wildlife in the world. With tourism in the region's wildlife parks growing in popularity, it is imperative to evaluate the socioeconomic and environmental costs and benefits of this expanding industry. This study conducted a cost-benefit analysis of the various impacts that tourism has brought to Kenya's national parks by monetarily valuating each impact. While the results of this cost-benefit analysis suggest that the benefits far outweigh the costs, even when non-measurable costs are considered, a number of fundamental issues must be addressed in order to improve the cost-benefit balance. The results are likely to be representative of the overall state of tourism in Kenya's national parks and expose key areas where improvements can be made. Improvements to tourism in Kenya's national parks can have positive implications for local people, the environment, wildlife species, tourists, and biodiversity conservation.

Keywords: tourism; national parks; Kenya; cost-benefit analysis

\section{Introduction}

Ecotourism is the fastest-growing sector in tourism, growing at $10-15 \%$ per annum [1,2]. Ecotourism is defined as responsible travel to natural areas that conserves the environment and improves the wellbeing of local people [3]. Indeed, the iconic megafauna of East Africa has attracted tourists to Kenya's 65 national parks and reserves, which are operated by the Kenya Wildlife Service (KWS), and have stimulated growth in the country's tourism industry [4,5]. These parks represent around $10 \%$ of Kenya's land mass, created as conservation areas to protect wildlife [6]. Tourism is important to the Kenyan economy, providing a large number of jobs and accounting for $15 \%$ of GDP in 2009 with tourist revenue totalling KES 73.68 billion [7].

Supporters believe that the socioeconomic and environmental contributions brought by tourism in the national parks seem to overwhelmingly support the tourism industry and the direction it is headed. However, further investigation into tourism in these areas reveals that the industry has brought with it both costs and benefits. Detractors have found that an established neo-colonial structure surrounding the industry has greatly disempowered local communities [8,9]. Culture and language have been marginalized with the growth of tourism, which has sparked social problems such as drug use [10,11]. The physical environment has been degraded by tourism, and species populations continue to drop with biodiversity loss [11-13].
The purpose of this study is to holistically investigate the costs and benefits of tourism in Kenya's national parks using a cost-benefit analysis. Each socioeconomic and environmental cost and benefit is investigated and given both a conservative and a liberal monetary valuation. By including both liberal and conservative estimations, this study is able to produce a range of possible scenarios in assessing the costs and benefits involved. This provides a broader representation of the net contribution of tourism in Kenya's national parks. It is hypothesized that while the socioeconomic and environmental benefits of tourism in Kenya's national parks are significant, the costs of associated problems created are also considerable and may outweigh the benefits when examined comprehensively in a cost-benefit analysis. While a cost-benefit analysis is admittedly less than complete, it is capable of providing valuable information to policy-making. As a holistic investigation of the socioeconomic and environmental impacts, it brings together a number of indicators into one study. This cost-benefit analysis can be used as a broad measure of the net contribution of tourism to Kenya's national parks [14,15]. Finally, given that improvements to the industry may benefit local people, the environment, tourist experience and biodiversity conservation, recommendations are made as to how benefits can be maximized and costs minimized. 
Table 1. Summary of monetary valuations for costs and benefits associated with tourism in Kenya's national parks.

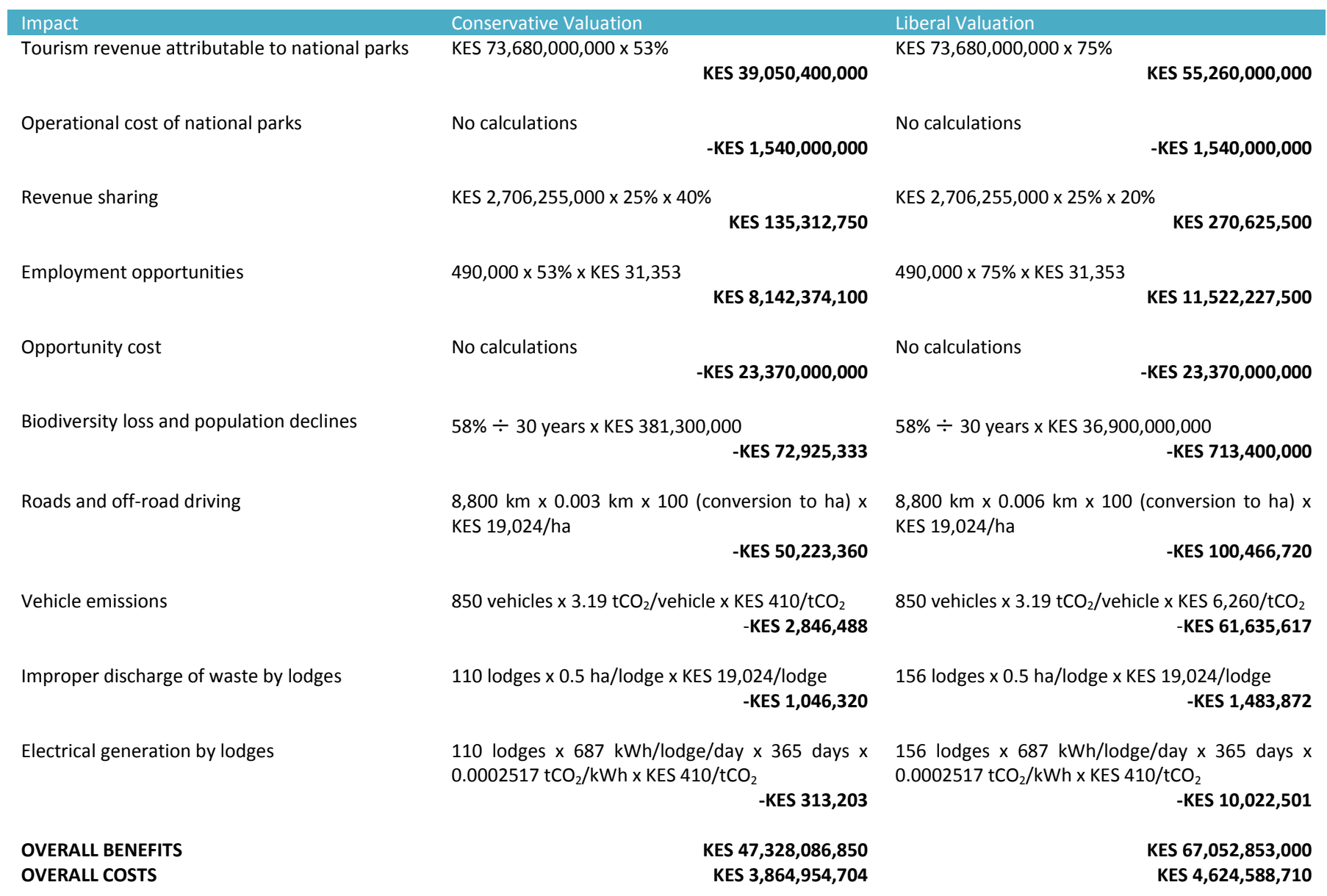

\section{Methodology}

Although there is no standardized procedure for conducting a cost-benefit analysis, the process typically follows several general stages: project definition, identifying project impacts, determining which impacts are economically relevant, quantification of impacts and monetary valuation of effects [16]. For this project, socioeconomic and environmental impacts were examined with regards to tourism in Kenya's terrestrial national parks and reserves. Data was obtained from a variety of available literature and publications. An in-depth review of the material found was conducted to establish which impacts were economically significant and to quantify each impact. Once relevant parameters were established for each cost and benefit, the appropriate figures were combined to produce two annual monetary valuations, a conservative and a liberal estimate.

Given the indirect nature of the valuation procedure used, assumptions had to be made in order to produce results. Due to the large variety of sources from which data was obtained, inconsistencies were not surprising. Data involving monetary values was found in both Kenyan Shillings (KES) and United States Dollars (USD). In order to work with this data, all data was converted to KES using the exchange rate USD 1 to KES 82, a rate which was chosen as a reflection of daily exchange rates observed over the month of January, 2012. This conversion rate was applied universally and did not correct for values given for past years. While this assumption may have affected the accuracy of the monetary valuations, it is unlikely that the result of the cost-benefit analysis would have been significantly skewed. Assumptions pertaining to each individual valuation are discussed in the following section, which explores each cost and benefit separately.

A number of impacts are omitted from this cost-benefit analysis. Some impacts inherently cannot be assigned a monetary valuation. In other cases, the magnitude of the assumptions that had to be taken in order to derive a monetary valuation removed any meaningfulness this valuation would have offered. Specific omissions will be detailed in the following section. 


\section{Monetary valuation}

This section details the conservative and liberal monetary valuation of each cost and benefit. See Table 1 for a summary of calculations detailed in this section.

\section{Socioeconomic impacts}

Tourism in Kenya's national parks has produced a number of economic benefits, the greatest of which is the contribution to Kenya's overall tourism revenue. This benefit was conservatively valued at KES 39,050,400,000 and liberally valued at KES 55,260,000,000 per year. These estimates were made by multiplying the country's tourism revenue of KES 73,680,000,000 reported for 2010 by the Republic of Kenya Ministry of Tourism and Wildlife (KMoT) with the percentage of tourists citing game park visitation as their primary motivation for visiting Kenya [7]. This percentage was reported conservatively as $53 \%$ by Akama and Keiti and liberally as 70-80\% (averaged to 75\%) by Ikiara and Okech [5,17]. It is assumed that tourists' primary motivation for visiting Kenya is indicative of the proportion of overall tourism revenue attributable to the national parks. However, just because tourists declare game park visitation as their primary motivation does not mean they only stay in the parks; they spend money elsewhere, meaning benefits and costs span a much larger area than the parks alone [17]. The operational cost of Kenya's national parks, reported to be KES 1,540,000,000 for 2010, must also be subtracted from this figure [18].

Revenue sharing, whereby $25 \%$ of park fees are ceded to a local authority, is a system aimed at providing local communities with a direct share of tourism benefits $[19,20]$. These payments are given to compensate for the communities' attenuated land use rights [21]. In 2010, income generated from park fees was reported to be KES $2,706,255,000$ [18]. This figure was multiplied by the $25 \%$ rate to yield a supposed compensation of KES 676,563,750. However, the compensation process has been found to be slow and inadequate, with local communities receiving very little of the money as most of the money is sifted away by county councils $[19,20]$. An interviewee in a study by Bruyere et al. [20] described these benefits as "very minimal". To account for this lack of efficiency in the process, conservative and liberal discount rates of $20 \%$ and $40 \%$ were applied to the compensation. These rates were adopted based on an analysis of the qualitative accounts that unanimously describe the system's gross inadequacy, as no credible rates could be found. Once these rates were applied to the initial valuation, revenue sharing was deemed to provide benefits worth KES 135,312,750 in the conservative valuation and KES 270,625,500 in the liberal valuation.

The KMoT reported in 2006 that the country's tourism industry generates a total of 490,000 jobs, of which 130,000 are formal positions and 360,000 are informal [22]. In order to determine how many of these employment opportunities are attributable to tourism in the national parks, this figure was multiplied by the conservative and liberal percentages of tourists citing game park visitation as their primary motivation for visiting Kenya, reported as 53\% and $75 \%$ respectively [5,17]. This assumes that tourists' primary motivation for visiting Kenya is indicative of the proportion of created jobs attributable to the national parks. This means that tourism has created 259,700 jobs in the conservative valuation and 367,500 jobs in the liberal valuation. Multiplied by the nation's annual average income of KES 31,353 , the conservative valuation of employment opportunities is KES 8,142,374,100 and the liberal valuation is $\operatorname{KES} 11,522,227,500$ [23]. These valuations do not take into account that most of the jobs created by tourism pay low wages and may not be stable [11].

An investigation of the true costs of tourism must consider the opportunity cost, which is the forgone value of the next best alternative to tourism [24]. In the case of Kenya's national parks, some $10 \%$ of total land mass was set aside as protected areas for biodiversity conservation, in which a booming wildlife tourism industry thrives [6,24]. Norton-Griffiths and Southey calculated the forgone gross revenues that could have been generated from agricultural and livestock production instead of setting aside land for parks and reserves to be KES 23,370,000,000 [24]. This figure was not modified further to give a conservative and liberal estimate as the methodology of the source was deemed to be a fair estimate of opportunity cost. Considering the limited ways in which the land could be used, it is safe to assume that agricultural and livestock production continues to be representative of how the land in national parks would have been developed.

One of the socioeconomic benefits that tourism has brought is improvements to infrastructure and social welfare. This includes improvements to schools and education, access to medical care and road access [20]. The most important aspect of these benefits to the local communities is tourism's impact on assets. Tourism has enhanced natural capital, such as the establishment of emergency grazing areas, raised human capital, funding for education, and increased access to physical capital, such as emergency access [25]. While these benefits have positive effects on quality of life, other impacts are more harmful. In some regions, booms in tourism have sparked social problems, such as an increase in drug use and prostitution [11]. In some areas, tourism has indirectly encouraged children to drop out of school, as it has become in their economic interests to take up work in tourism [11]. Furthermore, conflicting cultural norms are often experienced when tourists travel and interact with local people, which inevitably create negative feelings towards tourism [11]. While it is understood that culture is dynamic and ever-changing, tourism has likely influenced and diluted the cultures and languages of local people [10,11]. As these dynamics are far too complex and intertwined to characterize, no meaningful monetary valuation could be drawn for these impacts. 
Another negative aspect of tourism in Kenya's national parks is the neo-colonial structure that has been established, whereby a small number of foreign investors control tourism resources [26]. Even community-based enterprises, aimed at benefiting the wider community and establishing developmental routes in the long run, reflect such a structure [9,27]. This contributes to the economic, psychological, social and political disempowerment of local communities [8]. Furthermore, there is an over-reliance on the tourism in some regions, such that the local economy is completely dependent on the continued success and growth of the tourism industry [11]. While there are significant downsides to these issues, to generate monetary valuations for these impacts is beyond the scope of this study.

\section{Environmental impacts}

The establishment of conservation and management programs and raised awareness brought by tourism in Kenya's national parks has been beneficial, but there has still been a steady decline of wildlife populations and a net loss of biodiversity. Between 1977 and 1997, the total of all nonmigratory species in the Masai Mara dropped by 58\%; of these, the populations of warthog and buffalo have both declined by over $80 \%$, while those of the giraffe, eland, waterbuck and topi have all declined by over $70 \%$ [12]. Wildebeest populations have also been found to have declined by 75\% from 1980 to 2000 [13]. Ogutu et al. monitored the populations of seven ungulate species over 15 years and found that land-use change, including increased human settlement, is correlated with declines in species abundance [28]. While population densities of large predators, including lions and cheetahs, are relatively higher than other regions of Africa, declines are still experienced, largely due to increased human-predator conflict [29-32]. To monetarily valuate these losses, the $58 \%$ average loss documented by Ottichilo et al. was determined to be most representative of overall losses due to the study's comprehensiveness and its lengthy 30-year study period [12]. Assuming a linear population decline, the annual population decline rate was determined as $1.93 \%$. Moran calculated total tourist surplus of non-consumptive use of Kenya's national parks to conservatively range from KES $3,813,000,000$ to KES 36,900,000,000 per annum using willingness-to-pay estimates [21]. While tourism is not the single reason behind biodiversity loss, no figure could be found illustrating how much of these declines could be attributed to the tourism industry alone [28]. Thus, assuming tourism to be the sole factor leading to population declines, biodiversity loss can be estimated to conservatively cost KES 72,925,333 and liberally cost KES 713,400,000 per annum.

Additionally, the increased presence of tourists, vehicles and lodges has impacted the behaviors of wildlife. Traditional wildebeest breeding grounds have been affected so heavily that the schedule of the annual Great Migration has become unpredictable [5]. Leopards, which normally hunt in the day time, have been forced to hunt at night due to the noise pollution created by tourists and tour vehicles [5]. Frequently, packs of vehicles crowd around individual or groups of animals due to lack of regulation and enforcement, heavily affecting natural behavior [5]. Altered behaviors and migratory patterns may have consequences for the ecosystem. For instance, predators feeding on migrating wildebeest and zebra, such as lions and leopards, may experience a shortage of prey due to delays in the start of the Great Migration. Furthermore, the presence of tour vehicles may affect the hunting success of large predators. These impacts were determined to be contributing factors to overall population declines and biodiversity loss.

Off-road driving by tour vehicles to seek out rare animals scars the terrain, while paved roadways fragment habitats and disrupt migratory routes $[4,21,33]$. The Kenya Roads Board declared that $6,000 \mathrm{~km}$ of unclassified roads and $2,800 \mathrm{~km}$ of unclassified roads contracted by local authorities existed in all national parks and reserves in 1995, the latest year for which statistics were available [34]. Assuming a width of $3 \mathrm{~m}$ for single-lane roads in the conservative valuation and $6 \mathrm{~m}$ for double-lane roads for the liberal valuation, the total land area converted to roadways is 2,640 ha and 5,280 ha respectively. These areas can be translated to a monetary cost through a valuation of losses in ecosystem services from watershed and erosion protection, pharmaceuticals and carbon sequestration [24]. Costanza et al. reported in 1997 that the value of ecosystem services provided by grasslands and rangelands - the dominant biome type throughout Kenya's national parks and reserves was approximately KES 19,024 per hectare per annum [35]. Combining these figures produces an annual conservative cost of KES 50,223,360 and an annual liberal cost of KES $100,446,720$. These estimations were also made with the assumption that the conversion into roads has stripped the land of all ecosystem services.

Tour vehicles, like all other vehicles, emit greenhouse gases [36]. Because there are limited statistics on either the total number of tour vehicles in operation in Kenya's national parks or the average distance driven by tour cars, these had to be deduced from other data. The latest data available regarding the number of tour vehicles in operation is from 1992, during which 33,110 vehicles entered the Maasai Mara National Park at a rate of 90.71 cars per day [4]. This figure can be conservatively assumed to be representative of all tour vehicles in operation in the Maasai Mara National Park, as the entry statistic included repeat entries by the same vehicle over 1992. From 1995 to 2009, the Maasai Mara National Park has consistently accounted for an average of $10.67 \%$ of all visitor arrivals to Kenya's national parks [37]. Combining these figures, it can be deduced that roughly 850 tour vehicles operated in all of Kenya's national parks. The average vehicle in Nairobi, Kenya, travels $17,284.5 \mathrm{~km}$ per year [38]. Given the UNEP's declaration that the average vehicle in Kenya emits $184.65 \mathrm{gCO}_{2} / \mathrm{km}$, this means the average vehicle in Nairobi emits 3,191,582.925 $\mathrm{gCO}_{2}$ per year [36]. Combining these numbers with the estimated range of carbon dioxide pricing from KES 410 to KES 6,260 
per $\mathrm{tCO}_{2}$, this estimates a total cost of tour vehicle carbon emissions to be KES 1,112,267 in the conservative valuation and KES $169,824,121$ in the liberal valuation [39]. Despite the fact that commercial vehicles generally cover more distance than the average vehicle, these figures provide a conservative estimation of the cost of tour vehicle emissions. Emissions from civil aviation were also considered for inclusion. Globally, aviation emissions account for $4.9 \%$ of anthropogenic radiative forcing of climate change [40]. While data on the origins of international tourists to Kenya and general aviation emissions data are available, flight data could not be deduced meaningfully, deeming aviation emissions beyond the scope of this study. Monetary valuations would have required large assumptions to be made, so aviation emissions were not included as part of a larger estimate for transportation emissions.

Lodges are often built near watering holes or breeding grounds, driving animals away from their traditional territories [5]. Lack of infrastructure, access and regulation has led to the discharge of waste and sewage from lodges into surrounding areas, including waterways from which wildlife and local residents draw drinking water [5,33]. Furthermore, not a single hotel has a proper disposal system for waste oil from generators [5]. Due to a lack of available statistics pertaining to the total number of lodges in operation in Kenya's national parks, an estimation of this figure was deduced from other data. In 2009, a total of 6,242,800 hotel bed-nights were occupied, meaning $17,103.56$ beds are occupied per night [41]. In order to determine how many of these occupied bed-nights were attributable to tourism in the national parks, this figure was multiplied by the percentage of tourists citing game park visitation as their primary motivation for visiting Kenya, reported as 53\% and 75\% $[5,17]$. This assumes that tourists' primary motivation for visiting Kenya is indicative of the proportion of bed-night occupied in the national parks. Combining these figures, the number of beds occupied per night in the national parks is estimated to be $9,064.89$ in the conservative valuation and $12,827.67$ in the liberal valuation. In 1999, the Maasai Mara National Park's 25 hotels had a bed capacity of 2,057, averaging 82.28 beds per lodge [4]. Assuming full occupancy, this gives a conservative estimate of total lodges in operation in Kenya's national parks to be 110 in the conservative valuation and 156 in the liberal valuation. Given that no data is available for the area affected by waste disposal by lodges, a very conservative estimate of 0.5 ha per lodge was hypothesized. Combined with the KES 19,024 per hectare per annum value of ecosystem services lost by grasslands and rangelands, the conservative valuation of improper waste disposal by lodges is KES $1,046,320$ while the liberal valuation is KES $1,483,872$. It should be noted that, due to a lack of data, the valuations for this particular impact is likely to be an underestimation of the actual cost of improper waste disposal by lodges in Kenya's national parks.

The remote locations of most safari lodges means that most are unable to access urban electrical infrastructure, and electricity is generally produced locally using technologically inferior and highly polluting diesel power generators [5]. A hypothetical case study of a hotel's electrical usage by the United States Agency for International Development in 2009 showed that a small lodge with six rooms requires 50.12 $\mathrm{kWh}$ per day to operate [42]. Assuming that this figure represents general usage patterns and can be proportionally scaled up for a hotel with 82.28 beds, the average lodge in Kenya's national parks requires about $687 \mathrm{kWh}$ of energy per day. Using the estimation of 110 operational lodges in the conservative valuation and 156 lodges in the liberal valuation, it can be estimated that $75,570 \mathrm{kWh}$ and 107,172 $\mathrm{kWh}$ per day is used respectively. Then, assuming that all of this electricity is being generated from diesel fuel, which has a conversion factor to carbon dioxide of 0.2517 $\mathrm{kgCO}_{2} \mathrm{e} / \mathrm{kWh}$, these figures are translated to an estimated $6942.65 \mathrm{tCO}_{2} \mathrm{e}$ and $9845.95 \mathrm{tCO}_{2} \mathrm{e}$ emitted per year by lodges in the parks [43]. To get an estimate of carbon cost, the price of emitting carbon dioxide needs to be factored in. Using the prices of KES 410 per $\mathrm{tCO}_{2}$ for the conservative scenario and KES 6,260 per $\mathrm{tCO}_{2}$ for the liberal scenario, a conservative valuation of KES 2,846,488 and a liberal valuation of KES 61,635,617 are derived for emissions from electrical generation by lodges [37].

\section{Cost-benefit analysis}

The benefits associated with tourism in Kenya's national parks were conservatively valuated at KES $47,328,086,850$ and liberally valuated to be worth KES $67,052,853,000$ (Table 1). On the other hand, the costs were valuated conservatively at KES 3,864,954,704 and liberally at KES 4,624,588,710 (Table 1).Combining these valuations in a simple cost-benefit analysis demonstrates in all conservative and liberal pairings that the benefits brought by tourism in Kenya's national parks outweigh the costs (Figure 1). In a scenario where conservative benefits are coupled with liberal costs, the net benefit is lowered to KES $21,531,098,140$ per annum. In contrast, combining liberal benefits with conservative costs yields the greatest net benefit of KES 42,015,498,2956 per annum. 


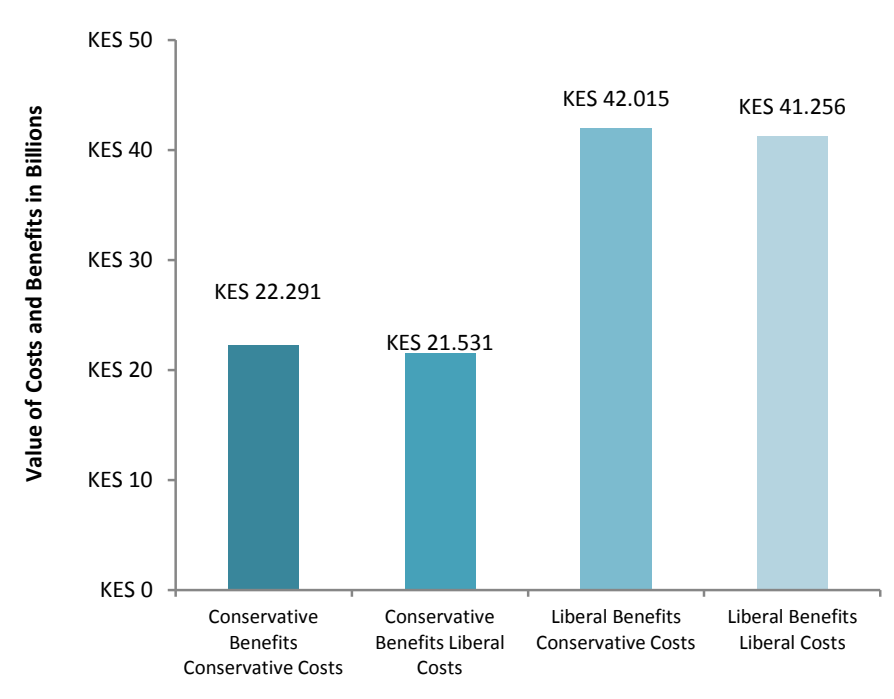

Scenarios Pairing Conservative and Liberal Valuations

Figure 1. Comparison of four scenarios pairing conservative and liberal valuations for costs and benefits.

\section{Discussion}

The very nature of cost-benefit analyses makes them highly controversial when used in making regulatory policy decisions. Heinzerling and Ackerman argue that the method itself lacks transparency and is weak in its attempts to put a dollar value on life, health and the natural world [15]. Ethical issues are raised at this practice [44]. It has been argued that cost-benefit analyses offer biased and misleading results, leading to inferior environmental protection and overall social welfare in the end [15]. In addition, while the discounting system used makes financial sense, it reduces the importance of environmental regulation and trivializes longterm risks [15]. Also ignored are the social and economic characteristics of stakeholders, with the result of ultimately reinforcing existing social and economic inequalities [15]. Moreover, many impacts have not been quantified and are inherently difficult to quantify, whereby major assumptions must be taken in order to produce numerical values $[15,44]$. However, despite these shortcomings, the results of a costbenefit analysis can contribute greatly to policy-making. Wells argues that even an incomplete or a partial cost-benefit analysis can be beneficial, yielding important and useful information valuable to policy-making [45]. Cost-benefit analysis offers a comparison of favorable and unfavorable effects of different policies [14]. Arrow et al. argue that, although cost-benefit analysis may not be sufficient in designing sensible policy due to the uncertainties and assumptions involved, it can help organize disparate information to the overall benefit of policy-making [14].

As outlined in the methodology, a number of costs and benefits are not accounted for in this study. Furthermore, this study could not address the possibility of overlapping estimates. For instance, the costs of wildlife declines may have been double counted by other costs such as roads or habitat loss due to waste disposal. While the study accounts for many of the larger issues surrounding tourism in Kenya's national parks, some costs and benefits may have been overlooked and not factored into the cost-benefit analysis. Therefore, the specific results of the cost-benefit analysis conducted in this study should not be taken as definite or final, especially given the assumptions and omissions made. Rather, the overall trend that the socioeconomic and environmental benefits seem to outweigh the costs should be observed as a broad representation of the impacts of tourism in Kenya's national parks.

Given the results of this cost-benefit analysis, it would be easy to assume that the benefits brought by tourism in Kenya's national parks far outweigh the costs, even when factoring in the several omissions made. However, these figures may not be accurate portrayals of the overall performance of wildlife tourism in Kenya. A number of fundamental issues must be addressed in order to maximize benefits and minimize costs.

Despite the large revenues experienced by the tourism industry, the way it is conducted largely dilutes socioeconomic benefits for the majority of locals. The neocolonial structure of the industry makes it difficult for local citizens and communities to be involved in decision-making processes $[9,26,46]$. Outsiders generally focus on maximizing benefits for themselves, neglecting the need for costs to be minimized, since many of the socioeconomic and environmental costs do not directly affect them [47]. Although some opportunities exist for local entrepreneurs and Kenya's development agenda has emphasized encouragement of micro and small businesses over the past two decades, a divide of power continues to disengage local communities from tourism [48]. With over 50\% of Kenyans living below the poverty line, and particularly with the incidence of poverty highest where tourist activity is highest, poverty is the most serious problem faced by local people $[9,17]$. It is crucial to many of these people's livelihoods and sustainable local community development that the neocolonial structure of tourism be addressed [17]. While tourism has the potential to aid in economic development and reducing poverty, a revamp of the current model of community-based enterprises, which emphasizes partnerships between foreign tour operators and local communities, is needed in order for this potential to be realized [17]. Poverty must be placed at the forefront of tourism development policies, and the involvement of local communities in tourism enterprises can create linkages to the local and national economies that are bypassed by many foreign operators $[17,47]$. Backed by a multitude of support organizations, the focal point of external intervention is the enhancement of conservation initiatives; a shift in focus towards the needs and priorities of local communities is imperative for community-based enterprises to achieve longterm sustainability [9]. A higher level of empowerment for local communities can be achieved by focusing on greater 
leadership, independence and local community priorities, and actively discouraging foreign elitism [9,49]. It is urgent for the government to find a different approach to tourism development policies to ensure equitable distribution of tourism opportunities and revenue among stakeholders [50].

Facilitating greater involvement of local stakeholders and emphasizing the priorities of local communities in the decision-making process may also address the lack of local representation on workforces. While the KMoT may boast that 490,000 jobs have been created by the tourism industry, these employment opportunities are inequitably distributed, with local people often losing out on these jobs to an outside workforce as evidenced by a lack of local representation in the staff of protected areas and lodges [20,22]. 64\% of local community members find tourism employment opportunities to be insufficient, with not a single community member identifying local employment opportunities to be a positive benefit of tourism [20]. Contrastingly, 33\% of protected area staff felt local job opportunities are a positive benefit of tourism [20]. These findings reveal symptoms of the industry's neo-colonial structure, further highlighting the need for local community priorities to be given greater antecedence [9]. Greater community involvement in the decision-making process can address the need to guarantee employment opportunities to locals.

Although $25 \%$ of park fees are supposedly ceded to a local authority for the benefit of local communities, the shortcomings of the established revenue sharing system, characterized as inefficient and inadequate, have been documented for over a decade $[19,20]$. With the majority of money sifted away in the administrative process, the description of revenue sharing benefits by local stakeholders as being "very minimal" reflects the abysmal degree of the system's weaknesses [20]. It is imperative for such compensation programs to be properly conducted. Drawing from studies in damage compensation programs for livestock depredation losses to protected predators, failure to compensate every time losses are suffered in a timely fashion is highly detrimental, exacerbating feelings of resentment against predators and conservation efforts [32,51]. In essence, if revenue sharing is not done properly, it may be better if it were not done at all. The current approach to revenue sharing should be reviewed and rejuvenated to become more organized, transparent and efficient. However, this may be far easier said than done. Addressing policy issues is difficult enough even in the most developed countries, let alone a government whose policies have been generally inconsistent, controversial, lacking in resources for implementation and enforcement and further hindered by corruption [20].

Although this study was unable to produce an estimate of the impact of infrastructure and social welfare improvements sparked by tourism in Kenya's national parks, these impacts are generally positive for local communities. Continued investment in these important and crucial changes is necessary to facilitate improvements in quality of life. These improvements should be equitably made to ensure that the benefits are felt throughout the country by different interest groups [20]. Social issues exacerbated by tourism, such as drug use, prostitution and the encouragement of children to work instead of complete school, must be addressed through policy and enforcement [11]. Although it is difficult to prevent some level of cultural dilution and marginalization of language as people continue to adopt and embrace Western values and customs, traditional values can be instilled through education [10,11]. Government policies must reflect the value of and the need to preserve culture and language, and must encourage tourism to be culturally sensitive and respectful [10].

It is absolutely crucial that species populations be continuously monitored and studied in an organized and structured manner by a government agency, such as the KWS. The collection of relevant data, such as species populations, species territory and migration patterns and behavioral changes, is critical for the impacts of tourism to be properly assessed and subsequent regulatory policies to be appropriately developed to help mitigate impacts and prevent further damage. Conservation plans can only be effective if detailed knowledge of species is incorporated [52]. While there are a number of studies documenting species populations, a centralized monitoring scheme must be established to yield consistent data. More research should also be conducted regarding the specific impacts of tourism on wildlife, in particular research that could quantify the causality between tourism and species population declines and biodiversity loss. Such detailed research will also allow for the evaluation of implemented solutions, with reduced ecological impact being the ultimate goal. Realistic, shortterm targets must be set for the recovery of wildlife populations and lost habitat.

It can safely be assumed that tourists who cite game park visitation as their prime motivation for visiting Kenya are most attracted to the wildlife. However, despite there being a total of 65 national parks and reserves in the country, the majority of tourists choose to congregate in a few specific parks, with the top five parks accounting for $54 \%$ of all visitor arrivals in 2009 and the top ten accounting for $80 \%$ [37]. In fact, only half of Kenya's parks had any visitation or visitor services [5]. Thus, a key strategy would be to rebrand and develop the rest of the national reserves, promoting and, in some cases, enabling tourists to visit other parks. This approach may minimize overconcentration of visitors in a select few parks, which will lessen the environmental impacts felt in these parks and allow for easier ecological recovery from anthropogenic damage. However, this will only be effective if a visitor cap or limit is set up for each park. The Galapagos Islands, Ecuador, serves as a case study where the number of visitors outmatched the ecosystem's carrying capacity for tourism. In 1974, a visitor limit of 12,000 was presented in the Galapagos National Park Management Plan. However, the visitor cap was surpassed every single year, leading to the abandonment of tourist limits altogether and a subsequent surge in visitor numbers. Not surprisingly, the rapid increase in visitors led to 
environmental erosion and disturbance to plants and animals, not to mention a general decline in tourism experience [53]. If visitor limits are to be implemented, these limits must be strictly adhered to.

While negative impacts of tourism on habitat and wildlife and are inevitable, the actions that cause damage can be reduced with proper training and enforcement of regulation. Tour drivers are currently hired by independent tour operators and are mostly given insufficient training. Standardized training by a government authority like the KWS and the implementation of a licensing scheme may reduce practices that excessively interfere with wildlife or damage the environment, such as driving too close to the animals, crowding them and driving over delicate habitat. Enforcement, whether it is by a government agency or by tour drivers themselves in the form of community policing, must be conducted to effectively implement regulations and restrictions [5].

Tour vehicles and power generation at lodges release greenhouse gases, contributing to global climate change. In recent years, the Kenyan government has acknowledged the fact that the current vehicle inspection system is inefficient, with $70 \%$ of the country's vehicles failing to meet the country's emissions criteria, and is working towards establishing an institutional and regulatory framework for vehicle inspections [54]. Foreign tourism operators should be encouraged to perform periodic inspections to ensure tour vehicles are in good shape. A strategic plan to support such a rapidly growing industry must be developed to establish sufficient infrastructure, both internally within parks themselves and externally to supplement the parks [50]. Increasing the energy efficiency of lodges can reduce the amount of electricity used, reducing the need for on-site power generation, as lodges are often built far from access to main electrical grids [5]. For some lodges, depending on location, it may be economically worthwhile to establish connections to the national electrical grid [55]. A system of waste disposal must also be established to prevent the discharge of garbage, sewage and waste oil directly into the environment [33]. The least environmentally-damaging solution is to collect waste and refuse from lodges and transport it to waste management facilities.

To ensure the long-term sustainability of tourism in Kenya's national parks, a structure for systematic review and examination of tourism operations and programs is needed to evaluate the costs and benefits. A tourism-specific environmental impact assessment process is proposed, which can systematically review the appropriateness of the tourism operation and evaluate construction impacts and operational impacts. With a tourism-specific system, the assessment process for new proposals can be accelerated if monitoring in and around the national parks is kept ongoing and dialogue with local communities - who are the most directly affected stakeholders in wildlife tourism - is continuously maintained. A holistic approach - in which moral, ethical, cultural and behavioral aspects are considered, especially where they apply to the local people's lives and environment - must be taken by such a process, with traditional and "extended expertise" given fair consideration for how a tourism operation is run [56]. Ongoing monitoring would ensure that, were socioeconomic and environmental factors to deteriorate beyond acceptable standards, tourism operations could be halted or held liable for costs. This would require the incorporation of aspects of the precautionary principle in the assessment structure, whereby a tourism operation could be halted and placed under review [57]. Additionally, were the neo-colonial structure of the tourism industry to persist, public participation mandated by an environmental impact assessment process would be able to draw some level of public participation [58]. It is recommended that legislation and standards are established to implement a tourism-specific environmental impact assessment process.

\section{Conclusion}

While the results of this cost-benefit analysis indicate that the benefits associated with tourism in Kenya's national parks outweigh the costs, the specific figures should not be taken as definite given the multitude of assumptions and uncertainties involved in the monetary valuation process. However, as a holistic investigation of the socioeconomic and environmental impacts involved, the results should be interpreted as representative of the overall state of tourism in Kenya's national parks.

A number of critical changes must be made to the existing tourism framwork to ensure benefits are maximized and costs are minimized. The neo-colonial structure of the tourism industry must be addressed to spur greater empowerment of local communities. Prioritization of the needs of local communities is imperative. Revenue sharing schemes must be reorganized to iron out inefficiencies and ensure that local communities actually benefit from these payments. Tourism operations must be culturally sensitive and respectful, and should promote the preservation of local culture and language. Systematic monitoring of species populations must be conducted for conservation to be successful, with realistic recovery targets needed to achieve long-term goals. Environmentally-damaging actions must be curbed and regulated, with supporting infrastructure established where necessary to reduce environmental degradation. Finally, the establishment of an environmental impact assessment process that is tourism-specific will be able to evaluate tourism operations to ensure the industry's sustainability. Further research regarding the holistic impacts of tourism should be conducted. Ultimately, improvements to the way tourism in Kenya's national parks is conducted will benefit local people, the environment, wildlife species, tourist experience and the effectiveness of biodiversity conservation. 


\section{Acknowledgements}

I would like to thank Dr. John Fryxell for his guidance and feedback on this research project. I am very grateful for the opportunity to have learned more about how human activity is affecting the people and ecosystems of East Africa. I would also like to thank Dr. Teresa Crease for providing me with advice and direction. In support of my project, I would also like to thank Dr. Richard Kuhn. I would also like to thank Michelle Lok, Christian Carlucci and everyone else who helped improve the paper.

\section{References}

1. Kamauro, O. (1996). Ecotourism: suicide or development? Voices from Africa Number 6: Sustainable Development Part 2. United Nations Non-Governmental Liaison Service.

2. Ramser, T. (2007). Evaluating Ecotourism in Laikipia, Kenya: Assessing the Socio-economic Impact and Conservation Attitudes. Thesis, University of Berne. Berne, Switzerland.

3. Sekercioğlu, C.H. (2002). Impacts of birdwatching on human and avian communities. Environmental Conservation, 29(3), 282-289.

4. Bhandari, M. (1999). Tourism raised problems in Masai Mara National Park in Narok, Kenya: Asia-Pacific Economic Conference.

5. Ikiara, M., \& Okech, C. (2002). Impact of tourism on environment in Kenya: status and policy. KIPPRA Discussion Paper Number 19. Kenya Institute for Public Policy Research and Analysis.

6. Weaver, D.B. (1999). Magnitude of ecotourism in Costa Rica and Kenya. Annals of Tourism Research, 26(4), 792-816.

7. Republic of Kenya Ministry of Tourism and Wildlife. (2011). Tourism performance overview 2010. Retrieved on January 12, 2012 from http://www.tourism.go.ke/ministry.nsf/pages/facts_figures

8. Scheyvens, R. (1999). Ecotourism and the empowerment of local communities. Tourism Management, 20, 245249 .

9. Manyara, G., \& Jones, E. (2007). Community-based tourism enterprises development in Kenya: an exploration of their potential as avenues of poverty reduction. Journal of Sustainable Tourism, 15(6), 628-644.
10. Eastman, C.M. (1995). Tourism in Kenya and the marginalization of Swahili. Annals of Tourism Research, 22(1), 172-185.

11. Van Marwijk, R., \& Joosten, M. (2003). A Small contribution? Small Tourism Entrepreneurs and Sustainable Development in Malindi. Thesis, Wageningen University. Wageningen, Netherlands.

12. Ottichilo, W.K., De Leeuw, J., Skidmore, A.K., Prins, H.H.T., \& Said, M.Y. (2000). Population trends of large non-migratory wild herbivores and livestock in the Masai Mara ecosystem, Kenya, between 1977 and 1997. African Journal of Ecology, 38, 202-216.

13. Homewood, K., Lambin, E.F., Coast, E., Kariuki, A., Kikula, I., Kivelia, J., Said, M., Serneels, S., \& Thompson, M. (2001). Long-term changes in SarengetiMara wildebeest and land cover: pastoralism, population, or policies? Proceedings of the National Academy of Sciences of the United States of America, 98(22), 1254412549 .

14. Arrow, K.J., Cropper, M.L., Eads, G.C., Hahn, R.W., Lave, L.B., Noll, R.G., Portney, P.R., Russell, M., Schmalensee, R., Kerry-Smith, V., \& Stavins, R.N. (1996). Is there a role for benefit-cost analysis in environmental, health, and safety regulation? Science, 272, 221-222.

15. Heinzerling, L., \& Ackerman, F. (2002). Pricing the priceless: cost-benefit analysis of environmental protection. Washington: Georgetown Environmental Law and Policy Institute.

16. Hanley, N., \& Spash, C.L. (1993). Cost-Benefit Analysis and the Environment. Cheltenham, UK: Edward Elgar Publishing.

17. Akama, J.S., \& Keiti, D. (2007). Tourism and socioeconomic development in developing countries: a case study of Mombasa Resort in Kenya. Journal of Sustainable Tourism, 15(6), 735-748.

18. Kenya Wildlife Service. (2010). Annual Report.

19. Sindiga, I. (1995). Wildlife-based tourism in Kenya: land use conflicts and government compensation policies over protected lands. Journal of Tourism Studies, 6(2), 45-55.

20. Bruyere, B.L., Beh, A.W., \& Lelengula, G. (2009). Differences in perceptions of communication, tourism benefits, and management issues in a protected area of rural Kenya. Environmental Management, 43, 49-59. 
21. Moran, D. (1994). Contingent valuation and biodiversity: measuring the user surplus of Kenyan protected areas. Biodiversity and Conservation, 3, 663-684.

22. Republic of Kenya Ministry of Tourism and Wildlife. (2006). Statistical analysis of tourism trends (globally and locally).

23. Kareithi, S. (2003). Coping with declining tourism, examples from communities in Kenya. London.

24. Norton-Griffiths, M., \& Southey, C. (1995). The opportunity costs of biodiversity conservation in Kenya. Ecological Economics, 12, 125-139.

25. Ashley, C. (2000). Applying livelihood approaches to natural resource management initiatives: experiences in Namibia and Kenya. London: Overseas Development Institute.

26. Akama, J.S. (2004). Neo-colonialism, Dependency and External Control of Africa's Tourism Industry. London, UK: Taylor \& Francis.

27. Rutten, M. (2002). Park beyond parks: genuine community-based wildlife eco-tourism or just another loss of land for Masaai pastoralists in Kenya. London: International Institute for Environment and Development.

28. Ogutu, J.O., Piepho, H.-P., Dublin, H.T., Bhola, N., \& Reid, R.S. (2009). Dynamics of Mara-Serengeti ungulates in relation to land use changes. Journal of Zoology, 278(1), 1-14.

29. Gros, P.M. (2002). The status and conservation of the cheetah Acinonyx jubatus in Tanzania. Biological Conservation, 103(2), 177-185.

30. Bauer, H., \& De Iongh, H.H. (2005). Lion (Panthera leo) home ranges and livestock conflicts in Waza National Park, Cameroon. African Journal of Ecology, 43, 208-214.

31. Frank, L., Hemson, G., Kushnir, H., \& Packer, C. (2006). Lions, conflict and conservation in Eastern and Southern Africa. Background Paper for the Eastern and Southern African Lion Conservation Workshop, Johannesburg, South Africa, 11-13 January 2006.

32. Hazzah, L., Mulder, M.B., \& Frank, L. (2009). Lions and warriors: social factors underlying declining African lion populations and the effect of incentive-based management in Kenya. Biological Conservation, 142, 2428-2437.
33. Okello, M.M., \& Kiringe, K.W. (2004). Threats to biodiversity and their implications in protected and adjacent dispersal areas of Kenya. Journal of Sustainable Tourism, 12(1), 55-69.

34. Kenya Roads Board. (1995). Kenya road network. Retrieved on February 3, 2012 from: http://www.krb.go.ke/road-network/road-network.html

35. Costanza, R., D'Arge, R., De Groot, R., Farber, S., Grasso, M., Hannon, B., Limburg, K., Naeem, S., O'Neill, R.V., Paruelo, J., Raskin, R.G., Sutton, P., \& Van den Belt, M. (1997). The value of the world's ecosystem services and natural capital. Nature, 387, 253-260.

36. United Nations Environment Programme. (2011). Developing a national fuel economy database and baseline: Kenya case study. Nairobi: United Nations Environment Programme.

37. Republic of Kenya Ministry of Tourism and Wildlife. (2010). Visitor arrivals, park stats. Retrieved on January $18, \quad 2012 \quad$ from: http://www.tourism.go.ke/ministry.nsf/doc/Visitor\%20Ar rivals,Parks\%20Stats.xls/\$file/Visitor\%20Arrivals,Parks \%20Stats.xls

38. International Sustainable Systems Research Center. (2002). Nairobi, Kenya vehicle activity study. La Habra: International Sustainable Systems Research Center.

39. Duong, M.H. (2009). What is the price of carbon? Five definitions. Survey and Perspectives Integrating Environment \& Society, 2(1).

40. Lee, D.S., Pitari, G., Grewe, V., Gierens, K., Penner, J.E., Petzold, A., Prather, M.J., Schumann, U., Bais, A., Berntsen, T., Iachetti, D., Lim, L.L., \& Sausen, R. (2010). Transport impacts on atmosphere and climate: aviation. Atmosperic Environment, 44, 4678-4734.

41. Republic of Kenya Ministry of Tourism and Wildlife. (2010). Hotel bed occupancy by zone. Retrieved on January $18, \quad 2012 \quad$ from: http://www.tourism.go.ke/ministry.nsf/doc/Hotel\%20Bed $\% 20$ Occupancy\%20by\%20zone.xls/\$file/Hotel\%20Bed\% 200ccupancy\%20by\%20zone.xls

42. United States Agency for International Development. (2009). Powering tourism: electrification and efficiency options for rural tourism facilities. Washington: United States Agency for International Development,

43. Carbon Trust. (2011). Conversion factors: energy and carbon conversions - 2011 update. London: Carbon Trust. 
44. Pearce, D. (1998). Cost-benefit analysis and environmental policy. Oxford Review of Economic Policy, 14(4), 84-100.

45. Wells, M.P. (1997). Economic perspectives on nature tourism, conservation and development. Washington: The World Bank Environment Department.

46. Coast, E. (2002). Maasai socioeconomic conditions: a cross-border comparison. Human Ecology, 30(1): 79-105.

47. Ashley, C., Boyd, C., \& Goodwin, H. (2000). Pro-poor tourism: putting poverty at the heart of the tourism agenda. London: Overseas Development Institute Natural Resource Perspectives.

48. Mshenga, P.M., \& Owuor, G. (2009). Opportunities for micro and small scale businesses in the tourism sector: the case of the Kenya coast. KCA Journal of Business Management, 2(2), 52-68.

49. Thompson, M., \& Homewood, K. (2002). Entrepreneurs, elites, and exclusion in Maasailand: trends in wildlife conservation and pastoralist development. Human Ecology, 30(1), 107-138.

50. Akama, J.S. (2002_. The role of government in the development of tourism in Kenya. International Journal of Tourism Research, 4, 1-13.

51. Gusset, M., Swarner, M.J., Mponwane, L., Keletile, K., \& McNutt, J.W. (2009). Human-wildlife conflict in northern Botswana: livestock predation by endangered African wild dog Lycaon pictus and other carnivores. Oryx, 43(1), 67-72.
52. Thirgood, S., Mosser, A., Tham, S., Hopcraft, G., Mwangomo, E., Mlengeya, T., Kilewo, M., Fryxell, J., Sinclair, A.R.E., \& Borner, M. (2004). Can parks protect migratory ungulates? The case of the Serengeti wildebeest. Animal Conservation, 7, 113-120.

53. Brandon, K. (1996). Ecotourism and conservation: a review of key issues. Washington: World Bank Environment.

54. Republic of Kenya Ministry of Environment and Mineral Resources. (2011). Motor Vehicle Emissions Control Stakeholders Workshop.

55. Parshall, L., Pillai, D., Mohan, S., Sanoh, A., \& Modi, V. (2009). National electricity planning in settings with low pre-existing grid coverage: development of a spatial model and case study of Kenya. Energy Policy, 37, 2395-2410.

56. Eden, S. (1996). Public participation in environmental policy: considering scientific, counter-scientific and nonscientific contributions. Public Understanding of Science, $5,183-204$.

57. Gustavson, K.R. (2003). Applying the precautionary principle in environmental assessment: the case of reviews in British Columbia. Journal of Environmental Planning and Management, 46(3), 365-379.

58. O'Faircheallaigh, C. (2010). Public participation and environmental impact assessment: purposes, implications and lessons for public policy making. Environmental Impact Assessment Review, 30(1), 19-27. 